\title{
Comment
}

\section{Considerações sobre a Educação Ambiental no Brasil}

\author{
Neiva Menezes Pereira Motal
}

Resumo: O objetivo deste trabalho é descrever sobre "como trabalhar a Educação Ambiental no ensino brasileiro", buscando compreender como o sistema educacional pode proporcionar aos indivíduos uma concepção crítica e integral de conservação do espaço no qual estar inserido. Tendo como alicerce as teorias de renomados escritores. Portanto, trata-se um estudo bibliográfico de caráter qualitativo, tendo como justificativa o interesse de ampliar os conhecimentos sobre o tema e questão. Tendo as Escolas brasileiras como elemento primordial para a prática efetiva da Educação Ambiental, garantindo, assim, a obtenção ou concepção de uma consciência ecológica por meio de uma aprendizagem, autônoma, crítica e participativa. Assinalando para a necessidade de um ensino agregado e globalizado, induzindo o educando, ainda, na pré-escolar a ser consciente da sua responsabilidade para com o meio ambiente, bem como a apreciar e assinalar os diversos relacionamentos sociais, inclusive ao que estar inserido.

Palavras chave: Educação Ambiental. Ensino Brasileiro, Escola.

\section{Considerations on Environmental Education in Brazil}

\begin{abstract}
The objective of this study is to describe "how work environmental education in Brazilian education", trying to understand how the education system can provide individuals a critical and integral conception of space conservation in which be inserted. With the foundation theories of renowned writers. Therefore, it is a bibliographic study of qualitative character, with the interest justification to broaden the knowledge on the topic and question. Having Brazilian schools as a core component for the effective practice of environmental education, thus ensuring obtaining or designing an ecological awareness through a learning, autonomous, critical and participatory. Pointing to the need for an aggregate and global education, inducing the student also in pre-school to be aware of its responsibility towards the environment as well as to appreciate and note the various social relationships, including the to be inserted.
\end{abstract}

Keywords: Environmental Education. Brazilian Education, School.

\section{Introdução}

Atualmente tem-se notado que o estrago feito em nome do progresso tem sido irreparável no território brasileiro e no mundo, mas entende que o ensino brasileiro pode reverter essa situação desagradável, apesar do homem, ainda, não consegue se incluir como natureza e nem busca ser parte integrante dela.

\footnotetext{
${ }^{1}$ Mestranda em Educação pela Anne Sulivan University. Pedagoga pela Universidade Regional do Cariri - URCA. Bacharel em Serviço Social pela Faculdade Leão Sampaio - FALS. Pós Graduada em Gestão e Supervisão Escolar pela Universidade Regional do Cariri - URCA. E-mail: neivafenelon@bol.com.br.
} 
Portanto, cabe ao ensino brasileiro conscientizar sua clientela por meio da Educação Ambiental que todos são sujeitos ativos e pensantes e que se deve buscar meios de conviver com a natureza, tirando proveito, sem desgastá-la. Pois, conscientizar os homens de que a natureza está incluída no ser de cada um, deve ser o objetivo primordial do sistema educacional, consciente de que é uma tarefa em longo prazo, para que as novas gerações não sejam prejudicadas pela degradação ambiental.

Esses fatores são o incentivo maior para desenvolver o tema "como trabalhar a educação ambiental no ensino brasileiro", que tem como intuito compreender como ocorrem as atividades pedagógicas direcionadas no ensino brasileiro para a conservação e higienização ambiental, justificando assim, é que se busca desenvolver este trabalho com base nas teorias de alguns autores, tais como Berna (2001), Carvalho (2002), Lutzemberg (2003) tendo em vista trata-se de uma pesquisa bibliográfica essencial para alicerçar este trabalho.

Assim, o objetivo é descrever sobre como trabalhar a Educação Ambiental desenvolvidas no campo educacional, visando compreender a conservação do meio ambiente e quais são as contribuições do ensino brasileiro na organização de espaços sociais, conceituação de natureza e os avanços na conscientização ambiental. Além de relatar sobre alguns procedimentos que devem ser aplicados na metodologia dos professores para explorar a Educação Ambiental na sala de aula.

\section{A Importância Educação Ambiental o Âmbito Escolar}

Acredita-se que a Educação Ambiental no âmbito educacional deve proporcionar aos indivíduos uma concepção crítica e integral do espaço no qual estar inserido, adequando procedimentos que sirvam de exemplo a toda comunidade e por meio da propagação e desenvolvimentos de projetos que promovam à adoção de atitudes conscientes em busca da melhoria de um ambiente saudável.

O assunto ambiental no Brasil tem procedência nos colapsos que antecede ao padrão desenvolvimentista, surgido em meio aos movimentos dos que anseio por um mundo onde a Educação Ambiental seja uma prática nas salas de aula e que os motivos principais estejam 
Id on Line Revista Multidisciplinar e de Psicologia

Id on Line Multidisciplinary and Psycology Journal

direcionados para a eliminação dos recursos naturais e desgasto das matérias-primas (REIGOTA 2009).

Sabe-se que as logo a realização da Conferência em Tbilisi a UNESCO (1998) determinou que a Educação deve buscar o que enfatizam Seara Filho (1987, p. 40-44) apud Grzebieluka, Kubiak e Schiller (2014, p.5):

[...] formar uma população mundial consciente e preocupada com o ambiente e com os problemas que lhe dizem respeito, uma população que tenha os conhecimentos, as competências, o estado de espírito, as motivações e o sentido de participação e engajamento que lhe permita trabalhar individualmente e coletivamente para resolver os problemas atuais e impedir que se repitam [...].

Compreende-se que Educação Ambiental consiste em um processo no qual as pessoas passam a conhecer a importância da preservação do Planeta Terra e como este é constituído, bem como da necessidade de evitar a degradação de seus recursos naturais e gerar a sua sustentabilidade.

Pode-se concordar com os Parâmetros Curriculares Nacionais (BRASIL, 1998, p.32) quando diz que "a educação ambiental pode ser visto como um novo momento de um projeto pedagógico que quer construir uma grande mudança de valores e de posturas educativas". Pois os conceitos de natureza bem como o meio ambiente são historicamente construídos pelos frutos da própria criação social. E quando se trata de agir com relação à qualidade de vida das pessoas, a conscientização sobre a preservação de recursos naturais pode e deve começar pela escola. Porque, enquanto os poderes constituídos pensam na questão de maneira abrangente, a escola deve trabalhar os subsídios da própria realidade (ISAIA, 2000).

As Escolas brasileiras precisam contribuir para uma prática efetiva da Educação Ambiental, garantindo uma aprendizagem, autônoma, crítica e participativa. E a colaboração dos professores torna-se alicerce fundamental para a qualidade e melhoria do ensino, uma vez que nos dias atuais se precisa de profissionais habilitados para lidar com as mudanças na forma de produzir, armazenar e transmitir saberes que esclareçam novos fazeres, pensamentos e aprendizagem.

O ensino direcionado para a preservação do meio ambiente, como um elemento de mutação social tem eficácia aceitável para que a comunidade adquira a condição durável e reflexiva sobre a disponibilidade e demanda dos recursos naturais e valoriza a seriedade de 
Id on Line Revista Multidisciplinar e de Psicologia

Id on Line Multidisciplinary and Psycology Journal

conservar as origens históricas e culturais de cada localidade e de cada sujeito (BERNA, 2001). Portanto, aposta-se na probabilidade de usar o expediente extraclasse na intenção de direcionar parâmetro para o desenvolvimento de projetos voltados para a conservação e proteção do meio ambiente. Sendo que os referidos projetos englobam o empenho sucessivo de todos os segmentos da Escola.

A Educação Ambiental no âmbito educacional precisa ser desenvolvida como uma importante ferramenta pelo aparelho educativo para elevar valores submersos ou jamais submergidos, com o intuito de induzir crianças e jovens a entenderem que a natureza é um benefício comum que deve ser compartilhado com alicerce em anseio de solidariedade e responsabilidade, por tratar de um elemento essencial para a vida de todos (BERNA, 2001).

Pessoa e Silva (1999, p.47) dizem que "existe uma nova filosofia de vida que dota o homem de uma consciência ecológica, bem como de uma postura ética perante a relação homem-natureza". Pode-se dizer que por meio da Unidade de Ensino é possível a obtenção ou concepção de uma consciência ecológica, pois, a escola representa o lugar excepcional onde necessita ocorrer de forma sistematizada ao exercício da Educação Ambiental.

\section{Definindo Educação Ambiental}

Quanto às definições de Educação Ambiental, Matsushima (2007 p.66) afirma que “não é difícil perceber a dificuldade teórica e prática em delimitar os conceitos e atividades da Educação Ambiental, e qualquer atividade que tenha alguma relação com a natureza acaba recebendo essa denominação". Nesse caso não é aceitável imaginar a definição Educação Ambiental sem a consideração de um processo, no qual é possível constituir valores, opiniões e atitude que é capaz entusiasmar a variação de comportamento das pessoas perante o relacionamento homem-natureza com o desígnio de torná-los aptos de determinar e prevenir dificuldades ambientais na contemporaneidade.

Para Lutzemberg, (2003, p.23) a Educação Ambiental "é um fenômeno múltiplo, que envolve aspectos físicos, sociais, econômicos, culturais, históricos e éticos, possui várias definições", contudo com peculiaridades comuns, assinalando para a necessidade de um ensino agregado e globalizado induzindo o educando ainda na pré-escolar a compreender o mundo. 
Id on Line Revista Multidisciplinar e de Psicologia

Id on Line Multidisciplinary and Psycology Journal

Dias (2003) e Reigota (2004) enfatizam que a Educação Ambiental deve ser um processo persistente que englobe exercícios interdisciplinares, que precisa mediar os conteúdos curriculares em todas as modalidades de ensino, voltado não exclusivamente ao uso dos bens naturais, mas fundamentalmente a participação dos habitantes da cidade, nas discussões e deliberação da dificuldade do meio em que se vive. Tendo o cenário escolar como transformadora de condutas da coletividade de consumo, para garantir a adequadamente a sobrevivência com qualidade da humanidade em todos os sentidos.

Portanto, pode-se dizer, que o alvo fundamental da Educação Ambiental é induzir o ser humano a envolver-se com a problemática natural do meio ambiente, direcionado sua capacidade a incentivação mútua na composição dos elementos, físicos, igualitário, financeiro, cultural, além de multiplicar os conhecimentos, sobre conduta ambienta e desempenho das habilidades pedagógicas, com intuito de notificar a precaução e solução das dificuldades ambientais.

Neste contexto, para Reigota (2004) é possível considerar a Educação Ambiental no ensino brasileiro como um processo, uma extensão que produz o conteúdo voltado para o exercício da educação, que aproveita diversas informações de maneira interdisciplinar para proporcionar a aquisição dos elementos relacionados ao homem-natureza em toda sua extensão. Entende-se assim que para o ensino brasileiro a Educação Ambiental é uma ação social adequada ao processo ensino-aprendizagem, esse método que adotado não admite o ensino estilhaçado em disciplinas que antes era sustentado pelo padrão positivista, apesar de ainda influenciar os meios científicos.

Portanto, para Dias (2003) o desenvolvimento do tema ambiental no ensino brasileiro deve ser por meio de projetos tendo como ponto de vista que defende uma análise global e um entendimento geral do fenômeno, com base em procedimento que ampliam as atividades agindo com condição e instrução de aperfeiçoamento, consistindo em uma formação para a vida, que instiga a atuação humana, bem como elemento de solução de problemas visíveis ao meio ambiente, oferecendo a todos dos cidadãos mais qualidade de vida, determinado por meio do bom discernimento e responsabilidade o exercício da cidadania.

Acredita-se que o ensino-aprendizagem brasileiro deve ser trabalho em sala de aula através de projetos voltados para a Educação Ambiental, com intuito de conduzir o aluno desde a pré-escola a apreciar e assinalar os diversos relacionamentos sociais, inclusive ao que estar 
Id on Line Revista Multidisciplinar e de Psicologia

Id on Line Multidisciplinary and Psycology Journal

inserido, entendendo os seus direitos e deveres para com tudo que o cerca. Neste sentido, Matsushima (2007, p.68) afirma que "para perceber estes valores o aluno precisa compreender que as questões ambientais estão inseridas no seu meio de convivência, e que, portanto, fazem parte do seu cotidiano", pois se espera que por meio dos projetos o aluno entenda a importância de modificar e manter limpo o espaço físico e social no qual convive.

Assim sendo, entende-se que no âmbito educacional é preciso o apoio de todos os segmentos escolares, especialmente, dos professores que devem buscar firmemente instigar os alunos a exercitar tarefas levando-os a valorizar os elementos naturais que são necessários para uma vida humana e justa, pois os professores têm consciência da importância de se trabalhar às questões ambientais e conduzem os alunos a perceberem que por trás da deterioração ambiental há uma coerência de um preceito econômico, que leva o indivíduo a praticarem o extermínio dos recursos naturais (REIGOTA, 2009).

Acredita-se que a responsabilidade do profissional da educação, na realização do processo da Educação Ambiental, precisa ter como alicerce uma relação mútua entre professoraluno para que realmente aconteça a promoção do elo entre escola e comunidade, proporcionando a uniformidade entre as diferentes realidades com que o aluno se encontrar no transcorrer da sua trajetória estudantil, principalmente quando englobam as outras disciplinas (BRASIL, 1998).

Sabe-se que a Educação Ambiental deve ser um aprendizado constante, tendo a escola como palco de propagação, porque é nela que os protagonistas (professores, alunos, diretores, funcionários e comunidade) se encontram inseridos.

Reigota (2004, p.24) afirma que:

Todos os professores, diretores, alunos, pais de alunos têm representações sociais que precisam ser conhecidas e discutidas, e que não se transmite conhecimentos sobre meio ambiente sem antes conhecer essas representações e colocá-las em discussão.

Nesse sentido, pode-se dizer que as exposições sociais, no âmbito escolar, exprimem informações que transportam o sujeito a se adaptar a uma vida sociável, higiênica e voltada para atividade positiva com o meio ambiente, já que, a Educação Ambiental produz uma percepção muito expressiva no recinto escolar, pois, trata-se de um estudo voltado para o incentivo ao aprendizado compartilhando entre orientandos e orientadores uma vez que o meio 
Id on Line Revista Multidisciplinar e de Psicologia

Id on Line Multidisciplinary and Psycology Journal

ambiente opera como elemento essencial que permite um intercâmbio entre o ser humano e a natureza (CARVALHO, 2002).

Ao longo da história tem-se visto e sentido que o homem explora os recursos naturais visando seus interesses, sem a preocupação com as consequências que suas transformações provocam. De modo geral o homem só tem pensado em lucros exorbitantes adquiridos através da exploração irracional do meio ambiente e nunca pensando nas reações da natureza (BERNA, 2001).

Acredita-se que a prática no ensino brasileiro, ultimamente tem articulado certos conteúdos, das áreas de conhecimento relacionado ao meio ambiente, visando incorporar hábitos dentro e fora da escola que possam ajudar a conscientizar a clientela de que se vive em constantes trocas ambientais, e o que se retira por necessidade, é apenas emprestado porque deve-se por obrigação devolver o que se gasta na natureza, para que as próximas gerações encontrem o mundo melhor do que se encontra hoje. Pois se sabe que o homem fala em progresso, rasga estrada, projeta edifícios, manipulam computadores, tudo isso em nome da civilização e muitas vezes não percebe que em nome desse progresso agride constantemente o meio ambiente (ISAIA, 2000).

O que se percebe, são municípios brasileiros sofrendo fortes devastações ambientais, principalmente no que se refere à preservação do nível da qualidade de vida, devido à urbanização acelerada, aumento populacional e tantos outros problemas. E já que é na escola que os problemas encontram soluções, nada será mais justo do que mostrar a capacidade que os homens possuem de atuar em conjunto aprendendo e ensinando a respeitar a natureza para seu fortalecimento futuro.

A prática de ensino sobre o meio ambiente contribui para que os alunos possam conhecer os espaços organizados pela sociedade e a replanejar o aproveitamento das áreas a serem exploradas, conforme os interesses políticos econômicos e culturais (CARVALHO, 2002).

Para Carvalho (2002) o meio ambiente é compreendido como tudo que cerca e envolve cada ser vivente e este é elemento integrante desse meio e o todo forma a própria natureza, mesmo que muitas vezes o ser humano se sinta superior, achando que se pode desfazer o "natural" sem nenhuma consequência. 
Id on Line Revista Multidisciplinar e de Psicoloqia

Id on Line Multidisciplinary and Psycology Journal

O uso aleatório dos recursos naturais, atendendo a visões imediatistas do modernismo, tem ocasionado sérios danos ambientais. Jamais a natureza foi tão explorada tanto no sistema capitalista e também na imposição de novas culturas marginalizando outras nações, e marcando comportamentos jamais vistos perante a trajetória histórica do meio ambiente.

A clientela do ensino brasileiro necessita se envolver mais com as várias transformações sofridas no sentido ambiental e buscar conscientizar o homem que tem destruído o natural para construir o artificial, para exibir a técnica de bem atender as necessidades vivenciais. E junto à produção do espaço, as florestas vão aos poucos desaparecendo e com elas todo o ecossistema que refugia a biodiversidade.

Sobre a conservação do espaço ambiental, é preciso que os alunos visitem lugares, observam gravuras, façam leitura dirigida de textos informativos sobre o assunto, elaborem comparações da linha do tempo, comentem poesias que tratam de contextos interessantes sobre meio ambiente, e troquem ideias sobre as notícias de jornais ou revistas. Que mostrem o interesse quando discutem e apresentam os trabalhos, elaborem comentários e demonstrem certa preocupação quanto à integração dos homens sob o ponto de vista social e ambiental. A atuação é dirigida para uma participação inteligente e ajustada.

A função dos professores é descobrir e dirigir os interesses dos educandos aproveitando o desenvolvimento mental para incentivá-los e conduzi-los ao objeto de estudo. As atividades devem ser debatidas e apresentadas para que haja eficiência nos trabalhos. E os conteúdos devem ser voltados para a formação de situações que proporcionem o desenvolvimento das habilidades de pensar e agir. Além disso, a clientela do ensino brasileiro deve ser dirigida para a apreensão e compreensão de conhecimentos generalizados; à aplicação na solução de problemas comuns à sua realidade. Tornando-se mais eficiente às variadas atividades com situações-problema que requerem reflexões e retenção dos conhecimentos. Que aconteçam mais aulas de campo, desempenhadas com a finalidade de trabalhar as imagens vivas, visando despertar o ver, ouvir, tocar, fazendo com que o aluno se conscientize e desperte seu interesse em aprender sobre o meio em que vive e valorize-o em prol das novas gerações.

Na prática desenvolvida em sala de aula deve ser incluído: leitura sobre a degradação ambiental, estudo das realidades de cada um, interpretação de gráficos, tabelas. Pois, aprender Educação Ambiental é importante por que os espaços vão se transformando cotidianamente. Novos modos de vida da comunidade são descobertas; as relações entre vários locais 
Id on Line Revista Multidisciplinar e de Psicologia

Id on Line Multidisciplinary and Psycology Journal

modificam-se e as necessidade e dificuldades não são as mesmas. Isso força a despertar o alunado para estudar essas modificações e processá-las cada vez mais depressa. A vida hoje exige das pessoas uma atualização constante de seus conhecimentos.

Desde cedo o aluno tem que ser despertado para as possibilidades de desenvolvimento de sua comunidade e como podem contribuir para o progresso não só do seu município, mas da pátria e do mundo em comunhão. Aos professores, cabe valorizar o aprendizado mostrando a grande importância da mistura de saberes, porque não só ajuda na formação como despertam diversos comportamentos de adequação social.

\section{Considerações Finais}

A problemática ambiental é algo que vem se fortalecendo há muito tempo e que agora, à luz do entendimento educacional, surge o desejo de vivenciar soluções e entendimento em salas de aula, assim, espera-se que os problemas ambientais sejam amenizados e que a natureza seja mais valorizada e traga em seu bojo, a necessidade de reeducar as sociedades e as futuras gerações para a busca de novas concepções educacionais visando incorporar a Educação Ambiental no cotidiano social, político, econômico e cultural do povo brasileiro.

Entendeu-se que as informações da Educação Ambiental devam ser rápidas e frequentemente discutidas em sala de aula e, que as ideias amadureçam e sejam refeitas, positivamente para o meio ambiente. Sentindo e tendo que conviver com tudo isso é que se precisam ampliar os conhecimentos dos alunos no espaço e no tempo, despertando o interesse desses por outros lugares e por outras pessoas, com vistas ao desenvolvimento da compreensão das dificuldades de outros povos e a buscarem amenizar suas necessidades.

Estudar o meio ambiente exige uma constante modernização, para que os procedimentos vivenciados apresentem resultados satisfatórios. Um dos maiores desafios tem sido fazer a sociedade entender que a natureza está em declínio e que a preocupação com o ambiente deve ser uma prioridade em todos os aspectos. 
Id on Line Revista Multidisciplinar e de Psicologia

Id on Line Multidisciplinary and Psycology Journal

\section{Referências}

BERNA, V. Como fazer educação ambiental. São Paulo: Paulus, 2001.

BRASIL, Parâmetros Curriculares Nacionais. Secretaria de Ensino Fundamental. Terceiro e quarto ciclos do ensino fundamental: Introdução aos parâmetros curriculares nacionais. Brasília: MEC/SEF, 1998.

CARVALHO, V. S. Educação ambiental e desenvolvimento comunitário. Rio de Janeiro, RJ: WAK, 2002.

DIAS, G. F. Educação Ambiental: princípios e práticas. 8 ed. São Paulo: Gaia, 2003.

GRZEBIELUKA, D.; KUBIAK, I.; SCHILLER, A. M. Educação Ambiental: A importância deste debate na Educação Infantil. 2014. Disponível em: http://cascavel.ufsm.br/revistas/ojs2.2.2/index.php/remoa/article/viewFile/14958/pdf. Acesso jun/2015.

ISAIA, E. B. I. Reflexões e práticas para desenvolver a educação ambiental na escola. Santa Maria: IBAMA, 2000.

LUTZEMBERG, J. A. O fim do futuro? Manifesto ecológico brasileiro. Revista de Antropologia, v. 46, n. 1, p. 21-25, 2003.

MATSUSHIMA, K. Dilema contemporâneo e educação ambiental: uma abordagem arquetipica e holística. Revista Brasileira de Direito Ambiental, v. 3, nº. 9, p. 65-73, jan./mar. 2007.

PESSOA, T. M. A.; SILVA, J. A. Elementos para a formação de educadores em educação ambiental. Revista do Mestrado em Educação. Universidade Federal do Piauí, no 4, p. 47-59, 1999.

REIGOTA, M. Meio ambiente e representação social. 6 ed. São Paulo: Cortez, 2004.

REIGOTA, M. O que é educação ambiental. 2 ed. Revista e ampliada. São Paulo: Brasiliene, 2009.

UNESCO. Educação Ambiental: as grandes orientações da conferência de Tbilise. Brasília: Instituto Brasileiro do Meio Ambiente e dos Recursos Naturais Renováveis, 1998.

Como citar este artigo (Formato ABNT):

MOTA, N.M.P. As contribuições de Vygotsky para o dsenvolvimento das crianças com deficiêncionsiderações sobre a Educação Ambiental no Brasil. Id on Line Revista Multidisciplinar e de Psicologia, Janeiro de 2017, vol.10, n.33, Supl 2. p. 329-338. ISSN: 1981-1179.

Recebido: 22/12/2016

Aceito: $19 / 01 / 2017$ 